\title{
Impacts of inland pollution input on coastal water quality of the Bohai Sea
}

\author{
Di Zhou ${ }^{\mathrm{a}}$, Miao Yu ${ }^{\mathrm{a}}$, Junbao Yu ${ }^{\mathrm{a}, *}$, Yunzhao $\mathrm{Li}^{\mathrm{a}}$, Bo Guan ${ }^{\mathrm{b}}$, Xuehong Wang ${ }^{\mathrm{a}}$, Zhikang Wang ${ }^{\mathrm{a}}$, Zhenbo Lv $^{\mathrm{a}}$, \\ Fanzhu Qu ${ }^{\mathrm{c}}$, Jisong Yang ${ }^{\mathrm{a}, *}$ \\ ${ }^{a}$ Key Laboratory of Ecological Restoration and Conservation of Coastal Wetlands in Universities of Shandong, Ludong University, The Institute for Advanced Study of Coastal Ecology, Yantai 264003 , \\ PR China \\ ${ }^{\mathrm{b}}$ Key Laboratory of Coastal Environment Processes and Ecological Remediation, Yantai Institute of Coastal Zone Research, Chinese Academy of Sciences, Yantai 264003, PR China \\ c Shandong Provincial Key Laboratory of Eco-Environmental Science for Yellow River Delta, Binzhou University, Binzhou 256601, PR China
}

\section{H I G H L I G H T S}

- About one third of the Bohai Sea area belongs to unclean seawater in 2017.

- The N, P, petroleum and heavy metals were main pollutants.

- The water quality of the Bohai Sea was great affected by inland pollutant inputs.

- The river and sewage outlet inland pollutants mainly derived from.

- River transportation and sewage outlet discharge are two main routes of inland pollutants inputs

\section{G R A P H I C A L A B S T R A C T}

The inland pollutants input is a key impact factor for coastal water quality of the Bohai Sea. A total of about $840,000 t$ of pollutants were carried into the Bohai Sea each year by 18 major rivers. The standard discharge rate of terrestrial source sewage outlets around Bohai Sea was no more than $50 \%$. Although the water quality improved gradually since 2012, about one third of the Bohai Sea area still belongs to the unclean seawater in 2017. The inorganic nitrogen, reactive phosphate, petroleum hydrocarbon and heavy metals are main pollutants in seawater of Bohai Sea.
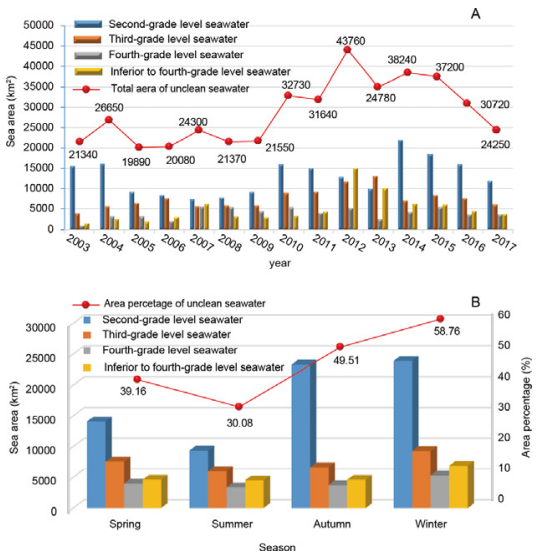

\section{A R T I C L E I N F O}

\section{Article history:}

Received 30 June 2020

Received in revised form 7 September 2020

Accepted 21 September 2020

Available online 3 October 2020

Editor: Paola Verlicchi

\section{Keywords:}

Inland pollution input

Coastal water quality

Inorganic nitrogen

\begin{abstract}
A B S T R A C T
Inland pollutants input is a key impact factor for the coastal water quality of the Bohai Sea. The coastal and inland water pollutant inputs were analyzed by using monitoring data of recent years from the State Oceanic Administration. The results showed that more than $56 \%$ of the Bohai Sea area was unclean seawater in 2012, although the water quality improved gradually after that time. In 2017, about one-third of the Bohai Sea area still had unclean seawater. Inorganic nitrogen, reactive phosphate, and petroleum hydrocarbons are the main pollutants in the seawater. A total of approximately $840,000 \mathrm{t}$ of pollutants was transported to the sea each year by major rivers during 2010-2017. Significant correlations $(p<0.05)$ were found between the third-grade level seawater area and the pollutants of $\mathrm{COD}_{\mathrm{cr}}$, petroleum, $\mathrm{NO}_{3}^{-}-\mathrm{N}, \mathrm{NH}_{4}^{+}-\mathrm{N}, \mathrm{NO}_{2}^{-}-\mathrm{N}, \mathrm{Cu}$, and $\mathrm{Pb}$ and between the inferior fourthgrade level seawater area and the pollutants of petroleum, $\mathrm{NO}_{2}^{-}-\mathrm{N}, \mathrm{Pb}$, and $\mathrm{NO}_{3}^{-}-\mathrm{N}$. The standard discharge rate of terrestrial-source sewage outlets was no more than $50 \%$. The low standard discharge rate of the major terrestrial-source sewage pollutants of $\mathrm{COD}_{\mathrm{cr}}, \mathrm{NH}_{4}^{+}-\mathrm{N}, \mathrm{TP}, \mathrm{BOD}_{5}$, and SS caused more than $80 \%$ of the monitored
\end{abstract}

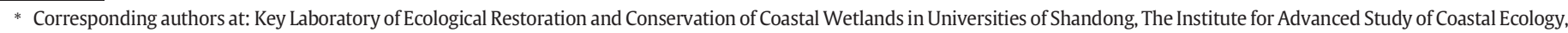
Ludong University, Yantai 264025, PR China.

E-mail addresses: junbao.yu@gmail.com (J. Yu), yjswill@126.com (J. Yang). 
sea areas adjacent to the selected key sewage outlets to not meet the water quality requirements of the marine functional area. The results suggest that implementing a coastal water management plan is necessary to reduce the heavy ecological burdens on the coastal zone of the Bohai Sea.

\section{Introduction}

The Bohai Sea $\left(37^{\circ} 10^{\prime}-41^{\circ} 10^{\prime} \mathrm{N}, 117^{\circ} 35^{\prime}-122^{\circ} 10^{\prime} \mathrm{E}\right)$ is located in the northwestern Pacific Ocean. It is a typical semi-enclosed shallow sea with a mean water depth of about $18.0 \mathrm{~m}$ (Kong and Ye 2014). The water exchange condition of the Bohai Sea is poor because the sea is surrounded by land on three sides. It contains three bays, namely, Laizhou Bay, Bohai Bay, and Liaodong Bay (Fig. 1). The coastal zone of the Bohai Sea is a developed area in China with a high population density of approximately 360 people per square kilometer (Hu and Liu 2007). Liaoning Province, Hebei Province, Shandong Province and Tianjin City enclose it in the north, west, and south, respectively. The fast economic development and rapid urbanization in the area has resulted in a large amount of inland source pollutants being discharged into the sea (Nie et al. 2012; Zhu et al. 2012). In addition, many offshore oil and gas fields, two large onshore oilfields (Shengli oilfield and Dagang oilfield), and large ports are widely distributed along the coastal areas of the Bohai Sea. Pollutants from oil spill accidents and vessels/ports have further exacerbated the pollution of the aquatic environment (Liu et al. 2016). Previous studies showed that about $18 \%$ of the Bohai Sea area was polluted to some extent. The most severely polluted areas were in three bays (Liu et al. 2011; Kong and Ye 2014). Inorganic nitrogen, reactive phosphate, and petroleum hydrocarbons are the main pollutants in the coastal water of the Bohai Sea (Peng 2015; Wang et al. 2019). Therefore, it is necessary to understand the effects of inland source pollutants on coastal water environments in the Bohai Sea to protect the marine environment and improve the water quality.

Nitrogen, phosphorus, heavy metals, and petroleum hydrocarbons are considered to be the most common terrestrial pollutants, and these have posed a grave threat to the marine ecology of the Bohai Sea (Zhan et al. 2010; Peng 2015; Zhou et al. 2018; Bai et al. 2020). Over-enrichment by anthropogenic emissions of nitrogen and phosphorus is the main driver of eutrophication in the water body (Wu et al. 2013; Ulloa et al. 2017). A recent study revealed that the long-term nutrient variations in the Bohai Sea have potential ecological impacts on the local red tide (Wang et al. 2019). Heavy metals and petroleum hydrocarbons both decrease water quality and contaminate sediment, where as an endogenous source of pollution, they can re-pollute overlying water slowly (Peng 2015; Yuan et al. 2017; Aagaard-Sorensen et al. 2018; Zhang et al. 2017; Lu et al. 2020). When heavy metals and petroleum hydrocarbons enter the food chain, they affect not only algae, fish, and various other organisms, but also human health (Fernandez-Tajes et al. 2011; Xue et al. 2015; Bayat et al. 2016). A previous study related to the spatial distribution and potential ecological risk of heavy metals in surface sediments of the coastal Shandong Peninsula suggested that most of the surface sediments have a $21 \%$ probability of being toxic ( $\mathrm{Li}$ et al. 2013). High levels of heavy metals were observed in the bays of the Bohai Sea, and terrestrial input was identified as one of the contamination sources of these heavy metals (Zhan et al. 2010). Although many studies have stated that inland pollution input is substantially responsible for the coastal water quality of the Bohai Sea, a clear relationship between the long-term variation of water quality and terrestrial pollutant input has not been revealed. Therefore, it is imperative to determine this relationship in detail in order to develop effective water quality management strategies and thus reduce the impacts of the pollutants. The purpose of this study was to reveal the current status and long-term variation of the coastal seawater quality of the Bohai Sea, the variation of total inland pollutants transported by major rivers and standard

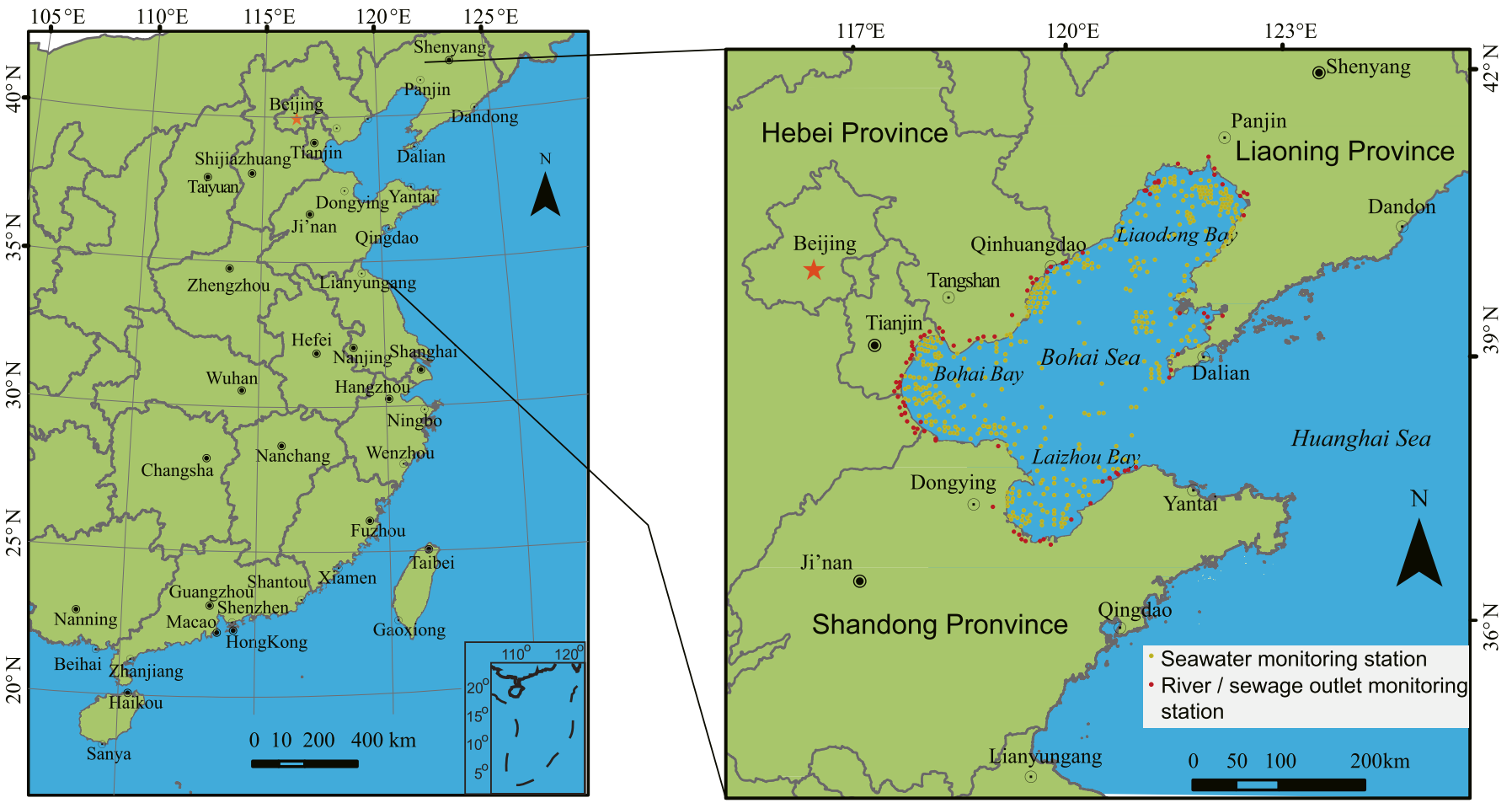

Fig. 1. The monitoring stations in/around the Bohai Sea. 
discharge rates of terrestrial-source sewage outlets, and the effects of inland pollution inputs on changes in coastal water quality.

\section{Material and methods}

Seawater quality data were derived from China's Marine Environment Bulletin (2004-2018). Inland pollutant input data were obtained from China's North Sea Marine Environment Bulletin (2007-2018) and the Environmental Monitoring Center, State Oceanic Administration.

At the time of this paper, there were 445 seawater monitoring stations in the Bohai Sea and 89 sewage outlet/river monitoring stations around the Bohai Sea (Fig. 1). The seawater monitoring period was in spring and autumn during 2003-2013 and in all seasons during 2014-2017. The river monitoring period was in the high water period (July), normal water period (November), and low water period (March) during 2010-2017. The monitoring frequency for sewage was more than once a day since 2014 .

The concentrations of ammonium nitrogen $\left(\mathrm{NH}_{4}^{+}-\mathrm{N}\right)$, nitrate nitrogen $\left(\mathrm{NO}_{3}^{-}-\mathrm{N}\right)$, nitrite nitrogen $\left(\mathrm{NO}_{2}^{-}-\mathrm{N}\right)$, and total phosphorus (TP) were determined by the standard methods of the American Public Health Association (APHA, 1998). Petroleum hydrocarbon concentrations were determined by ultraviolet fluorescence spectroscopy. The heavy metal concentrations of $\mathrm{Zn}, \mathrm{Cu}, \mathrm{Pb}, \mathrm{As}, \mathrm{Cd}$, and $\mathrm{Hg}$ were determined by inductively coupled plasma mass spectrometry (Agilent $7500 a, U S A)$. The chemical oxygen demand $\left(\mathrm{COD}_{\mathrm{cr}}\right)$ in water was determined by the potassium dichromate method, biochemical oxygen demand $\left(\mathrm{BOD}_{5}\right)$ was determined by the dilution and seeding method, and suspended solids (SS) were obtained by the gravimetric method according to the national standard method of China ((General Administration of Quality Supervision, Inspection and Quarantine of the People's Republic of China) and SAC (Standardization Administration of the People's Republic of China), 2008).

The seawater qualities were assessed by comparing the detected pollutant concentrations to the seawater quality standards of China (GB 3097-1997, China), which are shown in Table 1. The standard discharge rate of pollutants from terrestrial sewage outlets was assessed by comparing the pollutant concentrations in sewage to the integrated wastewater discharge standard of China (GB 8978-1996). The complication rate was calculated by comparing the numbers of monitoring sites which meets the environmental protection requirements to the total of monitoring sites. SPSS 24 software was applied to analyze the correlations among the grade of seawater areas and inland pollutant inputs by major rivers.

\section{Results and discussion}

\subsection{Coastal seawater quality changes}

The Bohai Sea is a unique inland sea in China. The water exchange of the sea is very poor (complete exchange takes at least 30 years) because it is semi-closed (Fig. 1). The limited water environmental carrying capacity of the Bohai Sea results in weak self-purification capability, unstable water quality, and even large-scale ecosystem collapse if large amounts of pollutants are transported into the sea (Zhao et al. 2011; Kong and Ye 2014; Li et al. 2014; Wang et al. 2018). The ecosystem of the Bohai Sea is being degraded rapidly, and the seawater has essentially lost its function as a fishing ground (Gao et al. 2014).

The Bohai Sea environment is severely polluted, and the polluted area increased continuously from 2003 to 2012 (Peng 2015). Based on the national seawater quality standard (GB3097-1997) of the People's Republic of China, the quality of seawater is divided into first-, second-, third-, fourth-, and inferior to fourth-grade levels. Except for the first-grade, other levels are considered to be unclean water. By 2012 , the area of unclean sea was $43,760 \mathrm{~km}^{2}$, about $56 \%$ of the area of the Bohai Sea, representing an increase of $22.42 \mathrm{~km}^{2}$ from the area in 2003 (Fig. 2 A). The sea area of inferior to fourth-grade level in 2012 was about 6 -fold larger than that in 2003 . The water quality has improved gradually since 2012 (Fig. 2 A). The total proportion of the unclean seawater area and sea area of inferior to fourth-grade level in 2017 were about $31.38 \%$ and $4.25 \%$, respectively. Compared with those of 2012, the total unclean seawater area and the sea area of inferior to fourth-grade level water in 2017 were lower by $44.58 \%$ and $34.04 \%$, respectively. As mentioned previously, inorganic nitrogen, reactive phosphate, and petroleum hydrocarbons are the main pollutants in the seawater (Peng 2015; Wang et al. 2019). However, the environmental pollution in the Bohai Sea has been transforming gradually from simple pollution of oil and heavy metals to combined pollution of industrial pollutants, sanitary pollutants, agricultural pollutants, etc. (Peng 2015; Liu et al. 2019). The great improvement of coastal water quality of the Bohai Sea that currently exists is partly a result of environmental protection policies. "Ecological civilization construction," with the ideal of "ecological priority and promote green," (to strengthen the protection of the ecosystem and fight the battle against pollution.) is being carried out by Chinese government. As a result of such policies, a large number of heavy polluting enterprises around the Bohai Sea have been relocated or renovated. For example, 123 and 228 polluting enterprises were closed and renovated, respectively, and 37 cement kilns and two 179 $\mathrm{m}^{3}$ blast furnaces were dismantled in Fengrun District, Tianjin, in 2007 (http://www.dh0315.com/show.asp?id=1956).

The monitoring results during 2014-2017 showed that heavy pollution appeared in winter (Fig. 2B). The average percentage of unclean seawater area to the total area of the Bohai Sea reached $58.76 \%$ in winter, which was higher than the values of other seasons. The low value was observed in summer (30.08\%). The seasonal change of inferior to fourth-grade seawater area was similar to the area of unclean seawater. Winter was the highest heavily polluted season (average heavily polluted seawater area of $6880 \mathrm{~km}^{2}$ ), while summer was the lightest polluted season (average heavily polluted seawater area of $4630 \mathrm{~km}^{2}$ ). The heavily polluted seawater area was larger in autumn than in spring.

Based on the monitoring data from China's Marine Environment Bulletin (2018), the unclean seawater area and inferior to fourth-grade seawater area of China in autumn with respect to inorganic nitrogen

Table 1

Seawater quality standard of China (GB 3097-1997, China) for selected pollutants ( $\mu \mathrm{L}^{-1}$ ).

\begin{tabular}{|c|c|c|c|c|c|}
\hline Pollutants & First-grade & Second-grade & Third-grade & Fourth-grade & Inferior to fourth-grade \\
\hline Inorganic nitrogen & $\leq 200$ & $200-300$ & $300-400$ & $400-500$ & $>500$ \\
\hline Reactive phosphate & $\leq 15$ & $15-30$ & $15-30$ & $30-45$ & $\geq 45$ \\
\hline Petroleum hydrocarbon & $\leq 50$ & $\leq 50$ & $50-100$ & $100-500$ & $\geq 500$ \\
\hline $\mathrm{COD}_{\mathrm{cr}}$ & $\leq 2000$ & $2000-3000$ & $3000-4000$ & $4000-5000$ & $\geq 5000$ \\
\hline $\mathrm{BOD}_{5}$ & $\leq 1000$ & $1000-3000$ & $3000-4000$ & $4000-5000$ & $\geq 5000$ \\
\hline $\mathrm{Hg}$ & $\leq 0.05$ & $0.05-0.20$ & $0.05-0.20$ & $0.20-0.50$ & $\geq 0.50$ \\
\hline $\mathrm{Cd}$ & $\leq 1.00$ & $1.00-5.00$ & $5.00-10.0$ & $5.00-10.0$ & $\geq 10.0$ \\
\hline As & $\leq 20$ & $20.0-30.0$ & $30.0-50.0$ & $30.0-50.0$ & $\geq 50.0$ \\
\hline $\mathrm{Pb}$ & $\leq 1.00$ & $1.00-5.00$ & $5.00-10.0$ & $5.00-10.0$ & $\geq 10.0$ \\
\hline $\mathrm{Cu}$ & $\leq 5.00$ & $5.00-10.0$ & $10.0-50.0$ & $10.0-50.0$ & $\geq 50.0$ \\
\hline $\mathrm{Zn}$ & $\leq 20.0$ & $20.0-50.0$ & $50.0-100$ & $100-500$ & $\geq 500$ \\
\hline
\end{tabular}



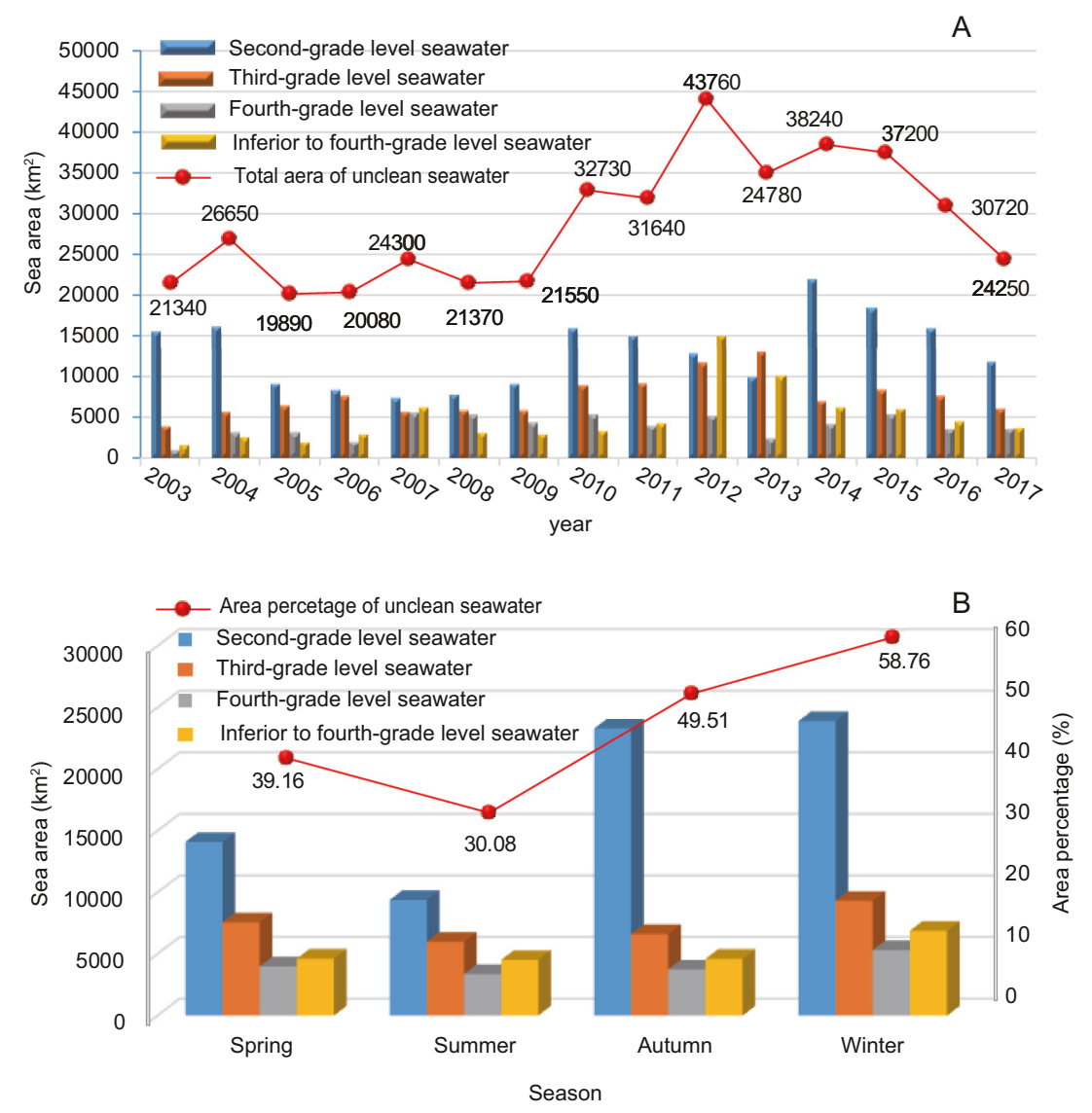

Fig. 2. The area change (A) and seasonal variation (B) of unclean seawater in Bohai Sea.

exceeding the standard were about 1.59 and 1.45 times the values in summer, respectively. Furthermore, with respect to phosphate exceeding the standard, the unclean seawater area and inferior to fourth-grade seawater area of China in autumn were about 1.67 and 0.58 times the values in summer, respectively. Through further analysis, the area affected and scope of inorganic nitrogen and reactive phosphate were enhanced in winter because portions of Bohai seawater were frozen, which blocked seawater exchange and caused accumulation of pollutants (Kong and Ye 2014; Wang et al. 2019).

\subsection{Inland pollution input}

The Bohai Sea is considered to be one of the most polluted marine areas in China due to the great amount of pollutants discharged into it annually and its geohydrologic condition, which limits selfpurification through the seawater exchange (Gao and Chen 2012). The two main routes of inland pollutants into the Bohai Sea are river transportation and sewage outlet discharge. Based on the results of an official investigation, there are 684 terrestrial pollution sources contributing pollutants to the Bohai Sea, including 125 rivers, 376 sewage outlets, and 183 drainage outlets. There is one pollution source per each $2 \mathrm{~km}$ of coastline.

The monitoring results of 18 major rivers along the Bohai Sea coast during 2010-2017 showed that a total of approximately 840,000 t of pollutants was carried into the sea each year. The annual $\mathrm{COD}_{\mathrm{cr}}$ input was approximately $796,250 \mathrm{t}$, about $94.85 \%$ of the total pollutants from rivers. The annual inputs of petroleum, $\mathrm{NO}_{3}^{-}-\mathrm{N}, \mathrm{NH}_{4}^{+}-\mathrm{N}, \mathrm{NO}_{2}^{-}-\mathrm{N}$, and TP were about 4650, 23,490, 16,260, 4250, and $5000 \mathrm{t}$, respectively. The annual transport volumes of the heavy metals $\mathrm{Zn}, \mathrm{Cu}, \mathrm{Pb}, \mathrm{As}, \mathrm{Cd}$, and Hg were about $610,164,147,80,12$, and 6 t, respectively. Gao et al. (2014) found that metal contamination in the Bohai Sea was closely associated with the rapid economic growth of the past decades. Non-point
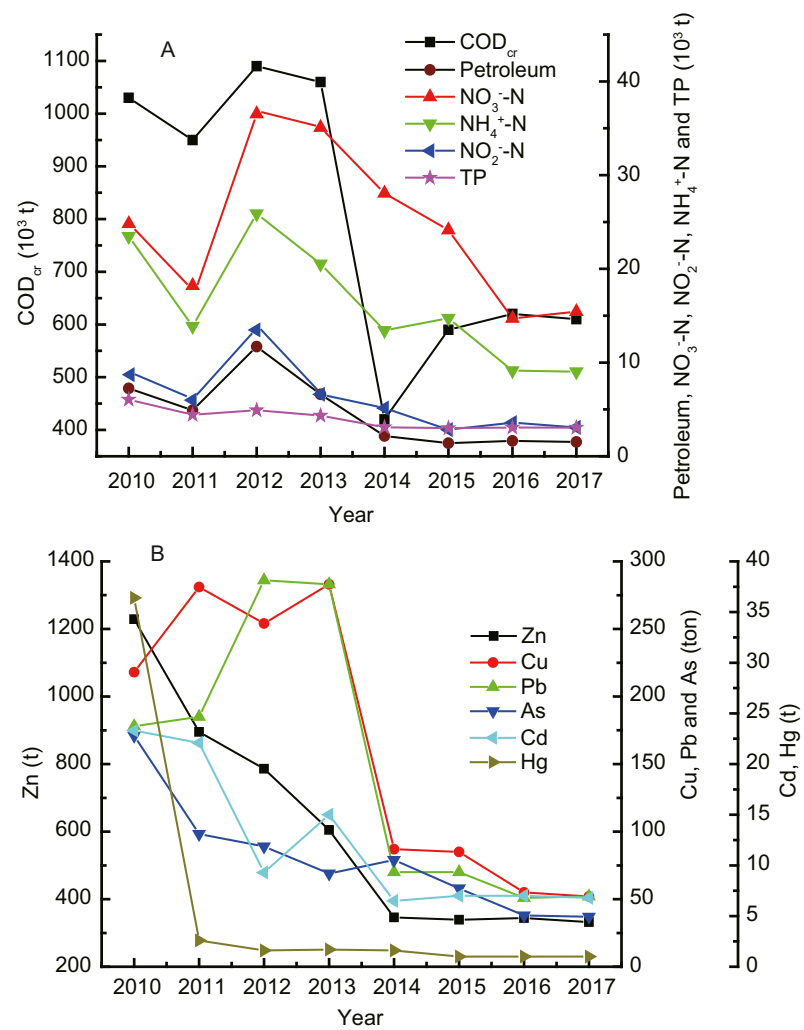

Fig. 3. Total amount of pollutants $\left(\mathrm{A}\right.$ : $\mathrm{COD}_{\mathrm{cr}}, \mathrm{NO}_{3}^{-}-\mathrm{N}, \mathrm{NH}_{4}^{+}-\mathrm{N}, \mathrm{NO}_{2}^{-}-\mathrm{N}$ and $\mathrm{TP}, \mathrm{B}: \mathrm{Zn}, \mathrm{Cu}, \mathrm{Pb}$, As, $\mathrm{Cd}$ and $\mathrm{Hg}$ ) carried into the sea by major rivers along the Bohai Sea during 2010-2017. 


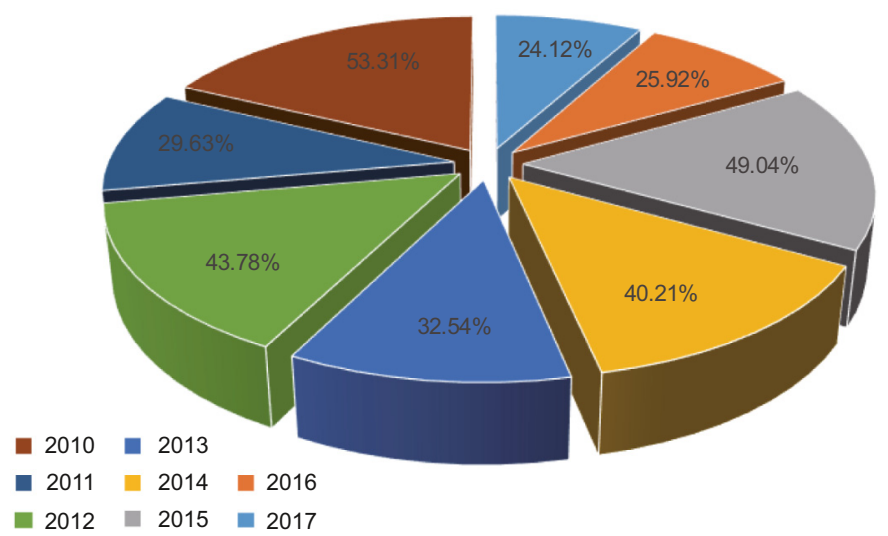

Fig. 4. Proportion of pollutants carried by the Yellow River in the total pollutants into Bohai Sea from major rivers during 2010 to 2017. (For interpretation of the references to colour in this figure legend, the reader is referred to the web version of this article.)

\section{Table 2}

The monitored terrestrial source sewage outlets and its standard discharge rate during 2010-2017 in Bohai Sea (IO: industrial sewage outlet, MO: municipal sewage outlet, SR: sewage river and other sewage outlet).

\begin{tabular}{ccccccccc}
\hline Year & \multicolumn{4}{c}{ Number of sewage outlets } & \multirow{2}{*}{$\begin{array}{l}\text { Monitoring } \\
\text { frequency }\end{array}$} & \multicolumn{2}{c}{$\begin{array}{l}\text { Standard discharge } \\
\text { rate (\%) }\end{array}$} \\
\cline { 2 - 5 } & Total & IO & MO & SR & Other & & 49 \\
\hline 2017 & 91 & 21 & 21 & 36 & 13 & 6 & 47 \\
2016 & 90 & 21 & 20 & 36 & 13 & 6 & 44 \\
2015 & 88 & 24 & 18 & 33 & 13 & 6 & 33 \\
2014 & 80 & 24 & 14 & 31 & 11 & 6 & 42 \\
2013 & 84 & 27 & 14 & 32 & 11 & 4 & 45 \\
2012 & 82 & 26 & 14 & 23 & 19 & 4 & 46 \\
2011 & 83 & 26 & 14 & 31 & 12 & 4 & 46 \\
2010 & 94 & 30 & 15 & 28 & 21 & 4 & \\
\hline
\end{tabular}

source pollution from coastal areas (fishing and harbor areas) played an important role for phosphate concentration (Liu et al. 2011). In general, the trend of the amount of pollutants carried by rivers into the Bohai Sea annually decreased from 2010 to 2017 (Fig. 3). Compared to 2010, in $2017, \mathrm{COD}_{\mathrm{cr}}$ and petroleum had decreased by $40.44 \%$ and $78.98 \%$, respectively, nitrogen and TP had decreased by $35.46-61.50 \%$ and $49.54 \%$, respectively, and heavy metals had decreased by 70.79-97.25\%. Among the monitored rivers, the Yellow River carried more than $24 \%$ of the total pollutants into the sea, and the highest proportion for this river reached 53.31\% in 2010 (Fig. 4). From 2014 to 2017, the amounts of $\mathrm{COD}_{\mathrm{cr}}$ and heavy metals, in particular, were reduced significantly due to the new policy implemented for strict control of pollutant discharges by the government of China (http://www. xinhuanet.com/politics/2015-01/22/c_127411041.htm).

The terrestrial sewage outlets along the Bohai Sea coast include industrial sewage outlets, municipal sewage outlets, sewage rivers, and other sewage outlets. Based on the monitoring results during 2010-2017, the standard discharge rate of terrestrial sewage outlets was no more than $50 \%$ (Table 2), which means that most of the terrestrial source sewage failed to meet the integrated wastewater discharge standard of China (GB 8978-1996). The standard discharge rates of $\mathrm{COD}_{\mathrm{cr}}, \mathrm{NH}_{4}^{+}-\mathrm{N}$, TP, BOD 5 , and SS were $58-78 \%, 84-95 \%, 72-88 \%, 70-81 \%$, and $69-92 \%$, respectively (Fig. 5). The standard discharge rate of $\mathrm{COD}_{\mathrm{cr}}$ was the lowest among the major pollutants from terrestrial sewage outlets. A previous study also revealed that $\mathrm{COD}_{\mathrm{cr}}$ pollution in the Bohai Sea resulted mainly from land-based point sources of pollutants (Liu et al. 2011).

Aside from river transport and sewage outlet discharge, recent studies have found that submarine groundwater discharge (SGD) is another important route of inland pollutant transport of heavy metals and nutrients to the Bohai Sea (Taniguchi et al. 2008; Liu et al. 2017; Wang et al., 2019a). The yearly SGD flux into the whole Bohai Sea was estimated to be $2.0 \pm 1.3 \times 10^{11} \mathrm{~m}^{3}$, and the dissolved inorganic nitrogen (DIN) flux was estimated to constitute $29 \%$ of the total fluxes from SGD (Liu et al. 2017). The SGD-derived heavy metal fluxes into Bohai Bay were estimated as 3.0-8.2 $\times 10^{5}$ and $0.6-1.8 \times 10^{3} \mathrm{~mol} \mathrm{~d}^{-1}$ for $\mathrm{Zn}$ and $\mathrm{Cd}$, respectively (Wang et al., 2019b).

\subsection{Effects of inland pollutant input on coastal water quality}

The annual inputs of $\mathrm{COD}_{\mathrm{cr}}$, petroleum, inorganic nitrogen $\left(\mathrm{NO}_{3}^{-}-\mathrm{N}\right.$, $\mathrm{NO}_{2}^{-}-\mathrm{N}, \mathrm{NH}_{4}^{+}-\mathrm{N}$ ), and the heavy metal $\mathrm{Pb}$ reached their peak in 2012 during the period of 2010-2017 (Fig. 3). Correspondingly, the unclean seawater area of the Bohai Sea also reached its peak in 2012 (Fig. 2A). A long-term nutrient variation study found that the surface DIN concentrations in the Bohai Sea were highest in winter of 2012 (Wang et al. 2019). Peng et al. (2015) found that petroleum, inorganic nitrogen, $\mathrm{Pb}$, and $\mathrm{Cu}$ increased during 2010-2012. The correlation analysis results showed that the relationship between the third-grade level seawater area and the pollutants of $\mathrm{COD}_{\mathrm{cr}}$, petroleum, $\mathrm{NO}_{3}^{-}-\mathrm{N}, \mathrm{NH}_{4}^{+}-\mathrm{N}, \mathrm{NO}_{2}^{-}-\mathrm{N}$, $\mathrm{Cu}(p<0.05)$, and $\mathrm{Pb}(p<0.01)$ and the relationship between the inferior to fourth-grade level seawater area and the pollutants of petroleum, $\mathrm{NO}_{2}^{-}-\mathrm{N}, \mathrm{Pb}(p<0.05)$, and $\mathrm{NO}_{3}^{-}-\mathrm{N}(p<0.01)$ were significant (Table 3$)$. This indicates that the amount of pollutants input into the sea by rivers was the key factor affecting the pollutant concentrations in the seawater, which determined the area of unclean water in the Bohai Sea. The inorganic nitrogen, petroleum hydrocarbon, and heavy metals of $\mathrm{Cu}$ and $\mathrm{Pb}$ in the seawater are derived mainly from river transport.

The environmental quality of water in sea areas adjacent to the sewage outlets were monitored annually. The results showed that no more than $20 \%$ of those sea areas met the environmental quality

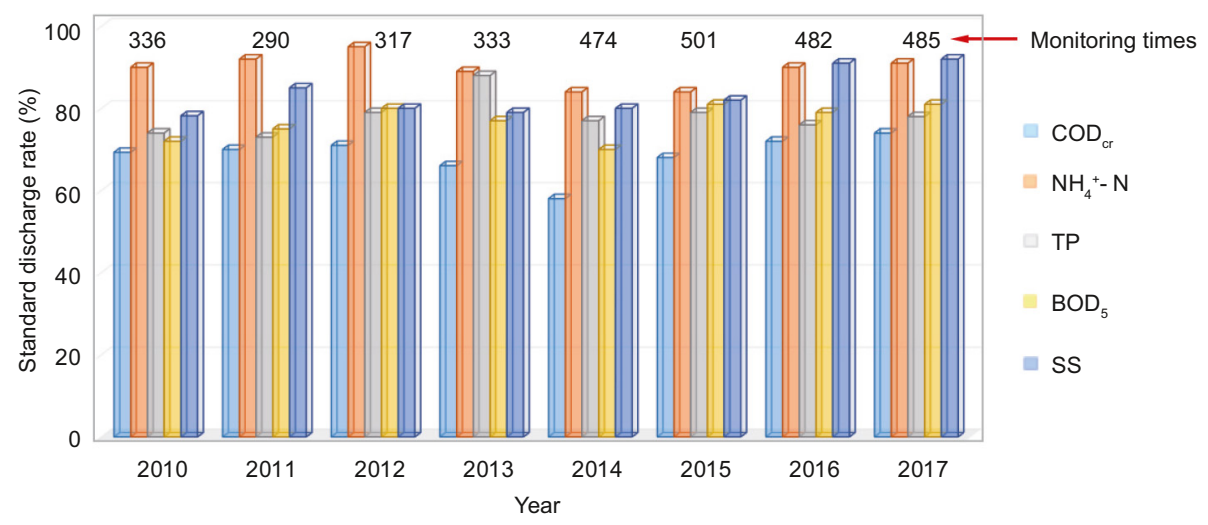

Fig. 5. Standard discharge rate of major pollutants from terrestrial source sewage outlets during 2010-2017 in Bohai Sea. 
Table 3

The correlation coefficients of different grade unclean seawater areas and inland pollutant inputs by major rivers.

\begin{tabular}{|c|c|c|c|c|c|c|c|c|c|c|c|c|}
\hline & $\mathrm{COD}_{\mathrm{cr}}$ & Petroleum & $\mathrm{NO}_{3}^{-}-\mathrm{N}$ & $\mathrm{NH}_{4}^{+}-\mathrm{N}$ & $\mathrm{NO}_{2}^{-}-\mathrm{N}$ & TP & $\mathrm{Zn}$ & $\mathrm{Cu}$ & $\mathrm{Pb}$ & As & $\mathrm{Cd}$ & $\mathrm{Hg}$ \\
\hline SGL & -0.66 & -0.44 & -0.40 & -0.26 & -0.24 & -0.31 & -0.21 & -0.47 & -0.58 & 0.13 & -0.22 & 0.08 \\
\hline TGL & $0.82^{*}$ & $0.77^{*}$ & $0.77^{*}$ & $0.76^{*}$ & $0.75^{*}$ & 0.55 & 0.42 & $0.83^{*}$ & $0.94^{* *}$ & 0.24 & 0.36 & 0.00 \\
\hline FGL & 0.04 & 0.27 & -0.25 & 0.41 & -0.67 & 0.33 & 0.37 & -0.03 & -0.04 & 0.51 & 0.08 & 0.44 \\
\hline IFGL & 0.48 & $0.73^{*}$ & $0.92^{* *}$ & 0.66 & $0.85^{*}$ & 0.23 & 0.06 & 0.48 & $0.73^{*}$ & -0.05 & -0.20 & -0.32 \\
\hline
\end{tabular}

SGL, second-grade level, TGL, third-grade level, FGL, fourth-grade level, IFGL, inferior to fourth-grade level, ${ }^{*} . P<0.05,{ }^{* *} . P<0.01$.

requirements of a marine functional area (Fig. 6). The main pollutants exceeding the standard were inorganic nitrogen, reactive phosphate, and $\mathrm{BOD}_{5}$. The lowest complication rates of both the integrated and water environmental quality occurred in 2012. Although the variations of standard discharge rate of terrestrial sewage outlets (Table 2) and major pollutants from terrestrial sewage outlets (Fig. 5) were not great, the lowest values of these did not appear simultaneously in 2012. The main reason for the lack of synchronicity may be that the discharge amounts of sewage and major pollutants were relatively large in 2012. Unfortunately, data of annual discharge amounts of sewage and major pollutants from terrestrial-source sewage outlets into the sea do not exist at present.

The results showed that the inland pollutant input was one of the important factors affecting the water environment quality of the Bohai Sea. A previous study revealed that the inland pollution input was more than 70\% of the total pollutants in the Bohai Sea (Li et al. 2016), and the pollutant loads from industrial sewage sites have shown stronger impacts on the water environment than those from general sewage (Liu et al. 2011). In addition, the Bohai Sea coastal area is one of the most developed zones of China, and industrial and municipal sewage from populous and developed cities, including Tianjin, Qinhuangdao, and Dalian, is discharged into the Bohai Sea (Zhang et al. 2009), resulting in heavy ecological pressure on the coastal water environment of the Bohai Sea.

\section{Conclusions}

The Bohai Sea has become one of the most polluted marine areas in China because of the huge input of pollutants from terrestrial and marine sources and its geohydrologic condition. Although the water quality of the Bohai Sea improved gradually after 2012, the present water quality is still not encouraging. Inorganic nitrogen, reactive phosphate, and petroleum hydrocarbons are the main pollutants in the seawater. The results of the study suggest that an ecological management plan should be implemented urgently and that ecological compensation mechanisms for the coastal water environment problems in the Bohai Sea should be developed. Remedial programs to address the problem of seawater quality must be considered. To control the inland pollution input strictly, the terrestrial pollutants from sewage outlets discharged directly into the sea must meet emission standards. However, it is difficult to control terrestrial pollutants that are transported by rivers. Thus, developing and implementing a specific water quality management plan for rivers debouching into the sea is a necessity. In addition to the requirement of standard discharge of industrial and municipal sewage into these rivers, the plan may involve modifications of agricultural structure and restrictions on the application of chemical fertilizers to control non-point source pollutants within the river catchment areas.

\section{CRediT authorship contribution statement}

Di Zhou: Investigation, Writing - original draft. Miao Yu: Data curation, Investigation. Junbao Yu: Conceptualization, Supervision, Writing - review \& editing. Yunzhao Li: Resources, Formal analysis. Bo Guan: Data curation, Software. Xuehong Wang: Investigation, Software. Zhikang Wang: Investigation, Data curation. Zhenbo Lv: Validation, Resources. Fanzhu Qu: Investigation, Data curation. Jisong Yang: Visualization.

\section{Declaration of competing interest}

The authors declare that they have no known competing financial interests or personal relationships that could have appeared to influence the work reported in this paper.

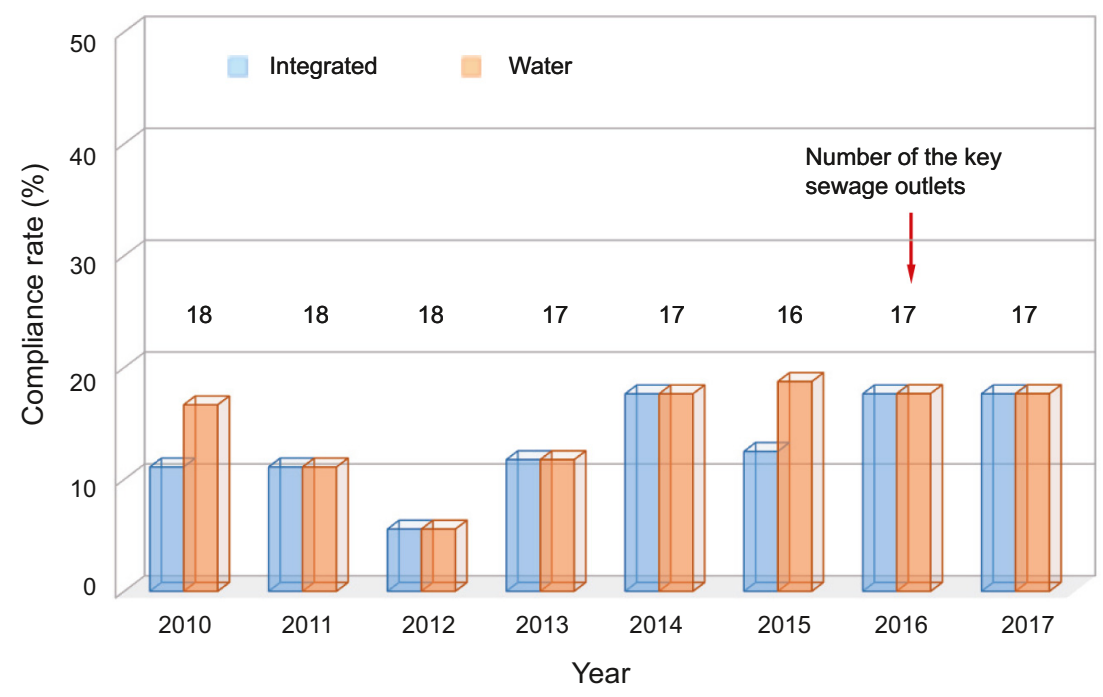

Fig. 6. The integrated and water environmental quality compliance rate of sea areas adjacent to the key sewage outlets. 


\section{Acknowledgements}

We are grateful for support from the National Key Research and Development Program of China (2017YFC0505902), Project of the Cultivation Plan of Superior Discipline Talent Teams of Universities in Shandong Province: "the Coastal Resources and Environment team for Blue-Yellow Area" and the Key Program from the National Natural Science Foundation of China (U1806218, U1706220).

\section{References}

Aagaard-Sorensen, S., Junttila, J., Dijkstra, N., 2018. Identifying past petroleum exploration related drill cutting releases and influences on the marine environment and benthic foraminiferal communities, Goliat field, SW Barents Sea, Norway. Mar. Pollut. Bull. 129 (2), 592-608.

APHA (Ed.), 1998. Standard Methods for the Examination of Water and Wastewater, 20th ed. APHA-AWWA-WPCF, Washington DC.

Bai, J.H., Yu, L., Ye, X.F., Yu, Z.B., Wang, D.W., Guan, Y.A., Cui, B.S., Liu, X.H., 2020. Dynamics of phosphorus fractions in surface soils of different flooding wetlands before and after flow-sediment regulation in the Yellow River Estuary, China. J. Hydrol. 580 (124256). https://doi.org/10.1016/j.jhydrol.2019.124256.

Bayat, Z., Hassanshahian, M., Hesni, M.A., 2016. Study the symbiotic crude oil-degrading bacteria in the mussel Mactra stultorum collected from the Persian Gulf. Mar. Pollut. Bull. 105 (1), 120-124.

Fernandez-Tajes, J., Rabade, T., Laffon, B., Mendez, J., 2011. Monitoring follow up of two areas affected by the prestige oil four years after the spillage. J. Toxicol. Environ. Health A. 74 (15-16), 1067-1075.

Gao, X.L., Chen, C.T.A., 2012. Heavy metal pollution status in surface sediments of the coastal Bohai Bay. Water Res. 46 (6), 1901-1911.

Gao, X.L., Zhou, F.X., Chen, C.T.A., 2014. Pollution status of the Bohai Sea: an overview of the environmental quality assessment related trace metals. Environ. Int. 62, 12-30.

GAQSIQ (General Administration of Quality Supervision, Inspection and Quarantine of the People's Republic of China), SAC (Standardization Administration of the People's Republic of China), 2008. The Specification for Marine Monitoring - Part 4: Seawater Analysis.

Hu, B. and Liu, X., 2007. The coastal zone division of Bohai Sea and population distribution statistics. Ocean Dev. Manage. (1): 73-75.

Kong, X.P., Ye, S.H., 2014. The impact of water temperature on water quality indexes in north of Liaodong Bay. Mar. Pollut. Bull. 80 (1-2), 245-249.

Li, G.G., Hu, B.Q., Bi, J.Q., Leng, Q.N., Xiao, C.Q., Yang, Z.C., 2013. Heavy metals distribution and contamination in surface sediments of the coastal. Shandong peninsula (Yellow Sea). Mar. Pollut. Bull. 76 (1-2), 420-426.

Li, K.Q., Shi, X.Y., Bao, X.W., Ma, O.M., Wang, X.L., 2014. Modeling total maximum allocated loads for heavy metals in Jinzhou Bay, China. Mar. Pollut. Bull. 85 (2), 659-664.

Li, B., Zhao, Y., Yang, K., Zhao, B., 2016. Current environmental status and the protection of the Bohai Sea. Ocean Dev. Manage. 33 (10), 59-62.

Liu, S.G., Lou, S., Kuang, C.P., Huang, W.R., Chen, W.J., Zhang, J.L., Zhong, G.H., 2011. Water quality assessment by pollution-index method in the coastal waters of Hebei Province in western Bohai Sea, China. Mar. Pollut. Bull. 62 (10), 2220-2229.

Liu, X., Guo, M., Wang, Y., Yu, X., Guo, J., Tang, C., Hu, X., Wang, C., Li, B., 2016. Assessing pollution-related effects of oil spills from ships in the Chinese Bohai Sea. Mar. Pollut. Bull. 110 (1), 194-202.

Liu, J.A., Du, J.Z., Yi, L.X., 2017. Ra tracer-based study of submarine groundwater discharge and associated nutrient fluxes into the Bohai Sea, China: a highly human-affected marginal sea. J. Geophys. Res. Oceans 122 (11), 8646-8660.
Liu, X.H., Liu, D.Y., Wang, Y.J., Shi, Y.J., Wang, Y.X., Sun, X.Y., 2019. Temporal and spatial variations and impact factors of nutrients in Bohai Bay, China. Mar. Pollut. Bull. 140, 549-562.

Lu, Q.Q., Bai, J.H., Zhang, G.L., Wu, J.J., 2020. Effects of coastal reclamation history on heavy metal in different types of wetland soils in the Pearl River Delta: levels, sources and ecological risks. J. Clean. Prod. 272 (122668). https://doi.org/10.1016/j. jclepro.2020.122668.

Nie, H.T., Tao, J.H., Due, M., 2012. Study on coastal zone sustainable development and its application. Appl. Mech. Mater. 170-173, 2280-2283.

Peng, S.T., 2015. The nutrient, total petroleum hydrocarbon and heavy metal contents in the seawater of Bohai Bay, China: temporal-spatial variations, sources, pollution statuses, and ecological risks. Mar. Pollut. Bull. 95 (1), 445-451.

Taniguchi, M., Ishitobi, T., Chen, J.Y., Onodera, S.I., Miyaoka, K., Burnett, W.C., Peterson, R., Liu, G.Q., Fukushima, Y., 2008. Submarine groundwater discharge from the Yellow River Delta to the Bohai Sea, China. J. Geophys. Res. Oceans 113 (C6). https://doi. org/10.1029/2007JC004498.

Ulloa, M.J., Alvarez-Torres, P., Horak-Romo, K.P., Ortega-Izaguirre, R., 2017. Harmful algal blooms and eutrophication along the mexican coast of the Gulf of Mexico large marine ecosystem. Environ. Dev. 22, 120-128.

Wang, Y., Li, K.Q., Li, Y., Lu, S., Wang, B.D., Wang, X.L., 2018. Assessing the total maximum allocated load of jurisdiction petroleum pollutants in the Bohai Sea. Ocean Coast. Manag. 151, 150-164.

Wang, Q.Q., Li, H.L., Zhang, Y., Wang, X.J., Zhang, C.C., Xiao, K., Qu, W.J., 2019a. Evaluations of submarine groundwater discharge and associated heavy metal fluxes in Bohai Bay, China. Sci. Total Environ. 695, 133873. https://doi.org/10.1016/j.scitotenv.2019.133873.

Wang, J.J., Yu, Z.G., Wei, Q.S., Yao, Q.Z., 2019b. Long-term nutrient variations in the bohai sea over the past 40 years. J. Geophys. Res. Oceans 124 (1), 703-722.

Wu, Z.X., Yu, Z.M., Song, X.X., Yuan, Y.Q., Cao, X.H., Liang, Y.B., 2013. The spatial and temporal characteristics of harmful algal blooms in the southwest Bohai Sea. Cont. Shelf Res. 59, 10-17.

Xue, J.L., Yu, Y., Bai, Y., Wang, L.P., Wu, Y.N., 2015. Marine oil-degrading microorganisms and biodegradation process of petroleum hydrocarbon in marine environments: a review. Curr. Microbiol. 71 (2), 220-228.

Yuan, L.L., Han, L.X., Bo, W.J., Chen, H., Gao, W.S., Chen, B., 2017. Simulated oil release from oil-contaminated marine sediment in the Bohai Sea, China. Mar. Pollut. Bull. 118 (1-2), 79-84.

Zhan, S.F., Peng, S.T., Liu, C.G., Chang, Q., Xu, J., 2010. Spatial and temporal variations of heavy metals in surface sediments in Bohai Bay, North China. Bull. Environ. Contam. Toxicol. 84 (4), 482-487.

Zhang, P., Song, J.M., Yuan, H.M., 2009. Persistent organic pollutant residues in the sediments and mollusks from the Bohai Sea coastal areas, North China: an overview. Environ. Int. 35 (3), 632-646.

Zhang, G.L., Bai, J.H., Xiao, R., Zhao, Q.Q., Jia, J., Cui, B.S., Liu, X.H., 2017. Heavy metal fractions and ecological risk assessment in sediments from urban, rural and reclamationaffected rivers of the Pearl River estuary, China. Chemosphere 184 (2017), 278-288.

Zhao, X.X., Wang, X.L., Shi, X.Y., Li, K.Q., Ding, D.S., 2011. Environmental capacity of chemical oxygen demand in the Bohai Sea: modeling and calculation. Chin. J. Oceanol. Limnol. 29 (1), 46-52.

Zhou, L.M., Sun, Y., Zhang, H.H., Yang, G.P., 2018. Distribution and characteristics of inorganic nutrients in the surface microlayer and subsurface water of the Bohai and yellow seas. Cont. Shelf Res. 168, 1-10.

Zhu, G.R., Xu, X.G., Ma, Z.W., Xu, L.F., Porter, J.H., 2012. Spatial dynamics and zoning of coastal land-use change along Bohai Bay, China, during 1979-2008. J. Coast. Res. 28 (5), 1186-1196. 